\title{
Grape seed and linseed, alone and in combination, enhance unsaturated fatty acids in the milk of Sarda dairy sheep
}

\author{
F. Correddu, G. Gaspa, G. Pulina, and A. Nudda ${ }^{1}$ \\ Dipartimento di Agraria, Sezione di Scienze Zootecniche, University of Sassari, Viale Italia 39, 07100 Sassari, Italy
}

\section{ABSTRACT}

This study evaluated the effect of dietary inclusion of grape seed and linseed, alone or in combination, on sheep milk fatty acids (FA) profile using 24 Sarda dairy ewes allocated to 4 isoproductive groups. Groups were randomly assigned to 4 dietary treatments consisting of a control diet $(\mathrm{CON})$, a diet including $300 \mathrm{~g} / \mathrm{d}$ per animal of grape seed (GS), a diet including $220 \mathrm{~g} / \mathrm{d}$ per animal of extruded linseed (LIN), and a diet including a mix of $300 \mathrm{~g} / \mathrm{d}$ per animal of grape seed and $220 \mathrm{~g} / \mathrm{d}$ per animal of extruded linseed (MIX). The study lasted $10 \mathrm{wk}$, with a 2 -wk adaptation period and an 8-wk experimental period. Milk FA composition was analyzed in milk samples collected in the last $4 \mathrm{wk}$ of the trial. The milk concentration of saturated fatty acids (SFA) decreased and that of unsaturated, monounsaturated, and polyunsaturated fatty acids (UFA, MUFA, and PUFA, respectively) increased in GS, LIN, and MIX groups compared with CON. The MIX group showed the lowest values of SFA and the highest of UFA, MUFA, and PUFA. Milk from ewes fed linseed (LIN and MIX) showed an enrichment of vaccenic acid (VA), oleic acid (OA), $\alpha$-linolenic acid (LNA), and cis-9,trans-11 conjugated linoleic acid (CLA) compared with milk from the CON group. The GS group showed a greater content of milk oleic acid (OA) and linoleic acid (LA) and tended to show a greater content of VA and cis-9,trans-11 CLA than the CON group. The inclusion of grape seed and linseed, alone and in combination, decreased the milk concentration of de novo synthesized FA C10:0, C12:0, and C14:0, with the MIX group showing the lowest values. In conclusion, grape seed and linseed could be useful to increase the concentration of FA with potential health benefits, especially when these ingredients are included in combination in the diet.

Key words: by-product, beneficial fatty acids, grape seed, extruded linseed, multivariate analysis

Received July 13, 2015.

Accepted November 19, 2015.

${ }^{1}$ Corresponding author: anudda@uniss.it

\section{INTRODUCTION}

Growing interest in the nutraceutical properties of food has directed the attention of researchers to improve the quality of dairy products. Polyunsaturated fatty acids, such as PUFA n-3, are recognized to be beneficial to human health, by reducing serum triglycerides and low-density lipoprotein cholesterol (Simopoulos, 1991). Ovine milk is a major source of CLA, such as cis-9,trans-11 CLA (rumenic acid, RA), which has several effects, such as antiatherosclerotic, anticancer, antidiabetic, and antiinflammatory activity (Bhattacharya et al., 2006).

Diet is the most important factor influencing milk fatty acid (FA) composition in dairy ewes. To increase the concentration of nutritional FA in milk, sources of unsaturated plant lipids, such as linseed, soybeans, safflower, and sunflower can be included in the diet (Nudda et al., 2014). In particular, linseed supplementation resulted in high concentrations of $\alpha$-linolenic acid (LNA), CLA, and vaccenic acid (C18:1 trans-11, VA), in the milk of sheep, cows, and goats (Zhang et al., 2006; Caroprese et al., 2010; Nudda et al., 2013a). Manipulation of ruminal biohydrogenation processes may also influence milk FA composition. As demonstrated by in vitro and in vivo studies, dietary polyphenols can affect the growth and activity of some strains of bacteria involved in the biohydrogenation pathway of FA, leading to a shift in the ruminal microbial population (Vasta et al., 2009a, 2010). In particular, it has been shown that polyphenols can inhibit the proliferation and activity of Butyrivibrio proteoclasticus, which is involved in the last step of biohydrogenation of PUFA, which consists of the enzymatic reduction of VA to stearic acid (C18:0, SA; Vasta et al., 2010; Buccioni et al., 2015). The consequent ruminal accumulation of PUFA and their biohydrogenation intermediates (Vasta et al., 2009b; Khiaosa-Ard et al., 2009) could enhance the extent of rumen escape of these FA and, consequently, could increase their concentration in milk, as demonstrated in studies on dairy cows and ewes (Moate et al., 2014; Buccioni et al., 2015).

Grape seed is a by-product derived from the winery and distillery industries, and it contains a high amount 
of polyphenols, mainly proanthocyanidins (Schieber et al., 2001). Therefore, the use of grape seed in ruminant nutrition could be useful to modulate ruminal biohydrogenation of PUFA and could be an alternative for the expensive management and disposal of this by-product. The inclusion of grape residue in sheep diets increased rumen accumulation of VA (Correddu et al., 2015), and in cows, reduced methane emissions and improved milk quality, by enhancing milk FA profile (Moate et al., 2014) and increasing antioxidant activity (Santos et al., 2014). Grape seed is also a good source of linoleic acid (C18:2n-6, LA), which could positively affect milk FA composition in dairy sheep.

Principal component analysis (PCA) and hierarchical cluster analysis (HCA) are useful methods to simplify the analysis of complex data sets composed of several variables, such as FA profile. In the last decades, the use of multivariate analysis has become a popular approach to discriminate the effects of dietary treatments throughout FA composition in meat (Coltro et al., 2005) and milk (Kadegowda et al., 2008) fat.

We hypothesized that dietary grape seed could enhance the effectiveness of linseed in increasing the concentration of PUFA in sheep milk. Therefore, the main objective of this work was to investigate the effect of inclusion of grape seed in the diet of lactating ewes, alone or associated with linseed, on milk FA profile. Moreover, multivariate analysis was used to test the hypothesis that data of milk FA could be a useful tool to discriminate between groups of ewes fed diets with different FA profiles.

\section{MATERIALS AND METHODS}

The experiment was conducted in a dairy sheep farm located in the north-west of Sardinia from February to April 2013. The sheep management and the chemical analysis of feeds have been previously reported in detail by Correddu et al. (2015). Briefly, 24 Sarda dairy ewes were selected to form 4 groups balanced for milk production $(1.75 \pm 0.02 \mathrm{~kg} / \mathrm{d}$ per head, mean $\pm \mathrm{SD})$, BW $(43.2 \pm 0.7 \mathrm{~kg}$, mean $\pm \mathrm{SD})$, DIM, and number of lactation (2-3 lactations). Each group was allocated to one of the following dietary treatments: (1) control diet (CON); (2) a diet containing $300 \mathrm{~g} / \mathrm{d}$ per animal of grape seed (GS); (3) a diet containing $220 \mathrm{~g} / \mathrm{d}$ per animal of extruded linseed (LIN); and (4) a diet containing both $300 \mathrm{~g} / \mathrm{d}$ of grape seed and $220 \mathrm{~g} / \mathrm{d}$ of linseed per animal (MIX). The ingredients, chemical composition, and FA profile of the experimental diets are reported in Table 1. All animals were fed a common ration, which included a commercial concentrate, beet pulp, mixed hay, and dehydrated alfalfa hay, and a mixed meal, which included corn, soybean, pea, grape seed, and linseed at varying amounts depending on the dietary treatment. The quantity of peas, soybeans, and corn was calculated to make isoproteic diets and to supply the same level of ME to each group. Linseed was offered at $220 \mathrm{~g} / \mathrm{d}$ per animal to provide $70 \mathrm{~g} / \mathrm{d}$ of fat per animal. Grape seeds were offered at $300 \mathrm{~g} / \mathrm{d}$ per animal to provide approximately $1 \mathrm{~g} / \mathrm{d}$ per animal of total grape seed polyphenols, considering that the total phenolic content of grape seed was $333.3 \pm 10.1 \mathrm{mg}$ gallic acid equivalents (GAE)/100 g of DM (mean $\pm \mathrm{SE}$ ).

\section{Milk Samples and FA Composition of Milk}

Individual morning milk samples were collected weekly and stored at $-20^{\circ} \mathrm{C}$ until analysis. Milk samples collected in the last $4 \mathrm{wk}$ of the trial were used to analyze milk FA composition.

Milk fat extraction and FAME preparation were performed as described by Nudda et al. (2005). The FAME were analyzed using a Turbo 3400 CX gas chromatograph (Varian Inc., Palo Alto, CA), equipped with a flame-ionization detector (FID), an automatic injector 8200 CX (Varian Inc.), and a capillary column (CPselect $\mathrm{CB}$ for FAME; $100 \mathrm{~m} \times 0.32 \mathrm{~mm}$ i.d., $0.25-\mu \mathrm{m}$ film thickness, Varian Inc.). The temperature program was as follows: $75^{\circ} \mathrm{C}$ for $1 \mathrm{~min}$, increased at $5^{\circ} \mathrm{C} / \mathrm{min}$ to $148^{\circ} \mathrm{C}$ and at $8^{\circ} \mathrm{C} / \mathrm{min}$ to $165^{\circ} \mathrm{C}$, held for $35 \mathrm{~min}$, increased at $5.5^{\circ} \mathrm{C} / \mathrm{min}$ to $210^{\circ} \mathrm{C}$, and finally, at $3^{\circ} \mathrm{C} /$ min to $230^{\circ} \mathrm{C}$ and held for $14 \mathrm{~min}$. Helium $(1 \mathrm{~mL} / \mathrm{min}$ flow rate) was used as carrier gas with a pressure of $255.10 \mathrm{kPa}$. Split ratio was 1:100. Injector temperature was set at $225^{\circ} \mathrm{C}$ and detector temperature was set at $285^{\circ} \mathrm{C}$. The FAME peaks were routinely identified by comparing their retention times with those of known standards and with published studies, as detailed in Nudda et al. (2005). Varian Star 3.4.1 software (Varian Inc.) was used to compute the retention time and area of each individual FAME.

Fatty acids were reported as grams per 100 grams of total FAME, and groups of FA were calculated as follows: SFA (sum of the individual saturated fatty acids); UFA (sum of the individual unsaturated fatty acids); MUFA (sum of the individual monounsaturated fatty acids); PUFA (sum of the individual polyunsaturated fatty acids); trans fatty acids (TFA; sum of individual trans fatty acids), branched-chain fatty acids (BCFA; sum of individual branched-chain fatty acids); odd- and branched-chain fatty acids (OBCFA; sum of individual odd- and branched-chain fatty acids); short-chain fatty acids (SCFA; sum of the individual fatty acids from C4:0 to C10:0); medium-chain fatty acids (MCFA; sum of the individual fatty acids from C11:0 to C17:0); long-chain fatty acids (LCFA; sum of the individual fatty acids from C18:0 to C22:6 (docosahexaenoic acid, 
Table 1. Ingredients, chemical composition, DMI, and fatty acid (FA) profile of diets

\begin{tabular}{|c|c|c|c|c|}
\hline \multirow[b]{2}{*}{ Item } & \multicolumn{4}{|c|}{ Diet $^{1}$} \\
\hline & $\mathrm{CON}$ & GS & LIN & MIX \\
\hline \multicolumn{5}{|c|}{ Ingredient ( $\mathrm{kg} / \mathrm{d}$ per animal, as fed) } \\
\hline \multicolumn{5}{|c|}{ Mixed meal } \\
\hline Corn & 0.15 & 0.17 & - & - \\
\hline Soybean & 0.12 & 0.24 & 0.04 & 0.16 \\
\hline Peas & 0.25 & 0.09 & 0.15 & 0.02 \\
\hline Grape seed & - & 0.30 & - & 0.30 \\
\hline Linseed & - & - & 0.22 & 0.22 \\
\hline Beet pulp & 0.40 & 0.40 & 0.40 & 0.40 \\
\hline Commercial concentrate & 0.50 & 0.50 & 0.50 & 0.50 \\
\hline Dehydrated alfalfa hay & 0.80 & 0.80 & 0.80 & 0.80 \\
\hline Mixed hay & 0.20 & 0.20 & 0.20 & 0.20 \\
\hline \multicolumn{5}{|c|}{ Chemical composition (\% of DM unless otherwise noted) } \\
\hline $\mathrm{DM}(\%)$ & 90.8 & 91.6 & 91.2 & 92.0 \\
\hline $\mathrm{NDF}$ & 41.8 & 42.8 & 43.7 & 44.5 \\
\hline NFC & 33.4 & 28.9 & 28.5 & 24.2 \\
\hline $\mathrm{ADL}$ & 4.6 & 8.9 & 5.0 & 9.4 \\
\hline $\mathrm{CP}$ & 18.0 & 17.9 & 17.9 & 17.9 \\
\hline Ash & 7.8 & 7.4 & 8.1 & 7.6 \\
\hline Ether extract & 2.0 & 3.2 & 5.1 & 5.8 \\
\hline FA & 1.8 & 2.3 & 3.7 & 4.5 \\
\hline ME supplied (Mcal/d) & 4.95 & 4.94 & 4.97 & 4.97 \\
\hline $\mathrm{DMI}(\mathrm{kg} / \mathrm{d})$ & 2.20 & 2.47 & 2.11 & 2.39 \\
\hline \multicolumn{5}{|c|}{ Major FA ( $\mathrm{g} / 100 \mathrm{~g}$ of total FA) } \\
\hline C16:0 & 18.98 & 14.88 & 11.99 & 11.50 \\
\hline C18:0 & 3.33 & 4.47 & 4.39 & 4.68 \\
\hline $\mathrm{C} 18: 1$ cis-9 & 22.79 & 23.52 & 21.78 & 21.91 \\
\hline C18:2n-6 (linoleic acid) & 41.53 & 47.50 & 23.84 & 33.46 \\
\hline C18:3n-3 (linolenic acid) & 8.25 & 5.04 & 34.45 & 24.93 \\
\hline SFA & 24.24 & 20.88 & 17.75 & 17.42 \\
\hline MUFA & 25.84 & 26.02 & 23.70 & 23.94 \\
\hline PUFA & 49.92 & 53.11 & 58.55 & 58.64 \\
\hline
\end{tabular}

${ }^{1}$ Diets: $\mathrm{CON}=$ control diet; GS = diet containing $300 \mathrm{~g} / \mathrm{d}$ per head of grape seed; LIN = diet containing 220 $\mathrm{g} / \mathrm{d}$ per head of linseed; MIX = diet containing $300 \mathrm{~g} / \mathrm{d}$ of grape seed and $220 \mathrm{~g} / \mathrm{d}$ of linseed per head.

DHA); PUFA n-3 (sum of individual n-3 fatty acids); PUFA n-6 (sum of individual n-6 fatty acids); CLA (sum of individual CLA); total C18:1 (sum of individual C18:1 isomers); total C18:2 (sum of individual C18:2 isomers); total C18:1-cis (sum of individual C18:1 cis isomers); and total C18:1-trans (sum of individual C18:1 trans isomers).

The nutritional properties of milk fat were estimated by the $\mathrm{n}-6: \mathrm{n}-3$ ratio and the following 3 indices: the atherogenic index (AI) and thrombogenic index (TI) were calculated according to Ulbricht and Southgate (1991) except for the substitution of C18:0 with C12:0, as suggested by Nudda et al. (2013b): AI $=[12: 0+(4$ $\times 14: 0)+16: 0] /[(\mathrm{PUFA})+(\mathrm{MUFA})]$, and $\mathrm{TI}=(14: 0$ $+16: 0) /[(0.5 \times$ MUFA $)+(0.5 \times \mathrm{n}-6)+(3 \times \mathrm{n}-3)+$ (n-3:n-6)]; the hypocholesterolemic to hypercholesterolemic ratio $(\mathbf{h : H})$ was calculated according to Fernández et al. (2007) as follows: h:H $=$ [(sum of 18:1 cis-9, 18:1 cis-11, 18:2n-6, 18:3n-6, 18:3n-3, 20:3n-6, 20:4n-6, $20: 5 n-3,22: 4 n-6,22: 5 n-3$, and $22: 6 n-3) /(14: 0+16: 0)]$.

To study the effect of the different diets on the capacity of desaturating SFA to $\Delta^{9}$-UFA, the $\Delta^{9}$-desaturation indices (DI) were calculated according to Schennink et al. (2008) as follows: C10 index $=[\mathrm{C} 10: 1 /(\mathrm{C} 10: 0$ $+\mathrm{C} 10: 1)] \times 100 ; \mathrm{C} 14$ index $=[\mathrm{C} 14: 1$ cis $-9 /(\mathrm{C} 14: 0+$ $\mathrm{C} 14: 1$ cis-9) $] \times 100 ; \mathrm{C} 16$ index $=[\mathrm{C} 16: 1$ cis $-9 /(\mathrm{C} 16: 0+$ $\mathrm{C} 16: 1$ cis-9) $] \times 100 ; \mathrm{C} 18$ index $=[\mathrm{C} 18: 1$ cis $-9 /(\mathrm{C} 18: 0+$ C18:1 cis-9)] $\times 100 ;$ CLA index $=[$ CLA cis-9,trans-11/ (C18:1 trans-11 + CLA cis-9,trans-11) $] \times 100$; total index $=[(\mathrm{C} 10: 1+\mathrm{C} 14: 1$ cis-9 $+\mathrm{C} 16: 1$ cis-9 $+\mathrm{C} 18: 1$ cis-9 + CLA cis-9,trans-11)/(C10:0 + C14:0 + C16:0 + $\mathrm{C} 18: 0+\mathrm{C} 18: 1$ trans-11+ C10:1 + C14:1 cis-9 + C16:1 cis-9 + C18:1 cis-9 + CLA cis-9,trans-11)] $\times 100$.

\section{Statistical Analysis}

Milk FA data were analyzed by the PROC MIXED procedure of SAS version 9.2 (SAS Institute Inc., Cary, $\mathrm{NC}$ ). The model included the fixed effect of diet (D; 4 levels), sampling date (S; 4 levels), and the diet $\times$ sampling date interaction $(\mathrm{D} \times \mathrm{S})$; moreover, to account for individual variability, the random effect of animal was nested within each treatment. The significance of group 
mean differences was assessed using Tukey honestly significant difference (HSD; $P<0.05$ ).

A multivariate approach was also adopted to better clarify the effect of the 4 dietary treatments on the milk FA composition, using a data set obtained from the average values of 4 sampling dates per animal. A total of 21 variables were analyzed (17 milk FA groups and 4 nutritional indices) using HCA and PCA. The HCA was performed on the milk FA profile using Euclidean distances and the average linkage method. A dendrogram was used to visualize the clustering of the experimental units. Furthermore, the correlation matrix of milk FA profiles was decomposed by the analysis of principal components (PC) as follows:

$$
\begin{gathered}
\mathrm{PC}_{j}=\alpha_{1 j} \mathrm{y}_{1}+\ldots+\alpha_{i j} \mathrm{y}_{i}+\ldots+\alpha_{(n-1) j} \mathrm{y}_{(n-1)} \\
+\ldots+\alpha_{n j} \mathrm{y}_{n},
\end{gathered}
$$

where y represents the observed variables, $n$ represents the number of variables $(21), \mathrm{PC}_{j}$ represents the generic $j$ th linear combination of the observed variables (scores) and $\alpha_{i j}$ the $i$ th coefficients of the eigenvector (loading) of correlation matrix, corresponding to the generic $j$ th eigenvalue (i.e., the variance explained by the $j$ th PC). The process of extraction was stopped when the variance explained by eigenvalues accounted for at least $80 \%$ of the total variance. Individual PC scores were then used in a one-way ANOVA including the fixed effect of treatments.

\section{RESULTS AND DISCUSSION}

\section{Milk FA Profile}

The FA composition of milk collected from the ewes of the 4 experimental treatments is reported in Table 2. The concentration of C4:0 increased in milk of ewes fed grape seed in combination with linseed (MIX) compared with CON $(P<0.05)$. The mean values found for this FA (2.8\% of FA) appear to be low compared with those of other studies, which ranged from 3.1 to $4.6 \%$ (Gómez-Cortés et al., 2009; Buccioni et al., 2015). This difference could be the consequence of the volatilization of C4:0 during the extraction and methylation processes used in our analyses. The inclusion of linseed, alone or in combination with grape seed, reduced the concentration of FA from C6:0 to C9:0 $(P<0.05)$. A large part of the FA from C10:1 to C17:1 cis-9 decreased in the GS, LIN, and MIX groups compared with CON $(P<$ 0.05), except for anteiso C13:0, iso C14:0, C16:1 trans-6 + trans-7, and C16:1 cis-7, which did not differ $(P>$ 0.05); C16:1 trans-8, which increased in MIX; C16:1 trans-9, which increased in LIN and MIX; and C16:1 cis-10, which increased in GS, LIN, and MIX compared with CON $(P<0.05)$. These changes resulted in reductions in SCFA and MCFA concentrations in the milk of ewes fed GS, LIN, and MIX, in decreasing order, compared with CON $(P<0.05)$. The LCFA concentration was higher in the treated groups than in the CON group $(P<0.05)$, in the following decreasing order: MIX $>$ LIN $>$ GS.

The concentration of total SFA decreased and that of UFA, MUFA, and PUFA increased in all groups compared with CON $(P<0.05)$, with the lowest SFA and the highest UFA, MUFA, and PUFA values being found in the MIX group $(P<0.05)$. The increase in UFA and PUFA, due to the dietary inclusion of grape seed, linseed, or both, resulted in higher UFA:SFA and PUFA:SFA ratios in all treated groups compared with CON $(P<0.05)$. The extent of increase of these ratios, especially that of PUFA:SFA in the milk from the MIX group compared with CON $(+187.5 \%)$ are very interesting, considering that it has been shown that replacing dietary SFA with PUFA is likely to reduce the occurrence of coronary heart disease (Mozaffarian et al., 2010).

The content of C18:0 increased in GS, LIN, and MIX compared with CON $(P<0.05)$. The concentration of most of the C18:1, C18:2, and CLA isomers increased in the milk of sheep fed linseed (LIN and MIX) compared with that of CON $(P<0.05)$, in accordance with other studies on cows (Caroprese et al., 2010; Ferlay et al., 2013), goats (Nudda et al., 2006, 2013a), and ewes (Mughetti et al., 2012) fed linseed. These results were likely because linseed is a rich source of $\mathrm{C} 18: 3$ FA ( $>55 \%$ of FA) and a moderate source of $\mathrm{C} 18: 1$ and $\mathrm{C} 18: 2$ (the sum is approximately $33 \%$ of FA). The presence of high concentrations of C18:1 isomers in the LIN and MIX groups can be partly explained by the biohydrogenation of $\mathrm{C} 18: 2$ and $\mathrm{C} 18: 3 \mathrm{FA}$ in the rumen and of the desaturation of SA in the mammary gland (Kennelly, 1996). The concentration of C18:1 trans-11 (VA) increased $(P<0.05)$ in LIN and MIX compared with CON. This is consistent with the high amount of C18:3n-3 (LNA) supplied by linseed, considering that this $\mathrm{FA}$ is a precursor of VA produced by the ruminal metabolism, and is in accordance with the experiments of Nudda et al. (2006, 2013a) and Mughetti et al. (2012), in which dietary linseed increased the levels of VA in milk of dairy goats and sheep. Moreover, VA is the precursor of the CLA cis-9,trans-11 formed in the mammary gland by $\Delta^{9}$-desaturase (Griinari and Bauman 1999). In fact, in our study, the concentration of CLA cis-9,trans-11 in the milk of the groups fed linseed (LIN and MIX) was higher $(P<0.05)$ than in the CON group. The concentration of CLA cis-9,trans-11 in milk 
from the LIN group (2.16\% of FAME) was comparable to that reported for sheep grazing high-quality pasture (2.20\% of FAME; Nudda et al., 2005) or fed a similar dose of linseed (2.33\% of FAME; Gómez-Cortés et al., 2009). Interestingly, the concentration of CLA cis9,trans-11 (1.73\% of FAME) in milk from sheep fed GS, which was numerically but not significantly higher than that in CON, was similar to that reported for sheep fed high amounts of linseed oil (about $40 \mathrm{~g} / \mathrm{d}$; Zhang et al., 2006) or fish oil (30 g/d; Mozzon et al., 2002). In the present work, milk from ewes fed MIX had a high concentration of CLA cis-9,trans-11 (3.0\% of FAME). As reported in the review by Nudda et al. (2014), concentrations of CLA cis-9,trans-11 $>3 \%$ of fat have been previously reached by using a very high dose of soybean oil $(140 \mathrm{~g} / \mathrm{d})$ associated with a high-concentrate diet. Dietary linseed also increased $(P<0.05)$ the concentration of LNA in milk from LIN (1.87\% of FAME) and MIX (1.42\% of FAME) compared with CON and GS. The extent of enrichment of LNA was consistent with previous studies where linseed was included in the diet of sheep (Mele et al., 2007; Gómez-Cortés et al., 2009)

The presence of a moderate concentration of polyphenols in the diet increased the level of beneficial FA, mainly LNA, in milk from ewes (Cabiddu et al., 2009) and cows (Dschaak et al., 2011). This effect has been explained by the capacity of polyphenols to inhibit the activity of some strains of ruminal bacteria involved in the biohydrogenation of UFA (Cabiddu et al., 2009; Vasta et al., 2009a; Minieri et al., 2014). In the current work, the inclusion of GS, alone or in combination with linseed, increased the concentration of PUFA compared with the CON group $(P<0.001)$. However, this increase was likely due to the high amount of LA in grape seeds (about $75 \%$ of FA), considering that GS and MIX also increased LA and, consequently, PUFA n-6, in milk compared with CON and LIN $(P<0.05)$. This is in agreement with the findings of Moate et al. (2014) and Santos et al. (2014), who showed increased levels of LA in milk of dairy cows fed grape residue.

The concentration of PUFA n-3, which was the lowest in CON and GS, was higher in milk from sheep fed linseed alone than in combination with grape seed $(P<0.001)$. This is likely due to the lack of effect of grape seed in reducing the extent of biohydrogenation of LNA, as suggested by the decreased level of LNA in milk of MIX compared with $\operatorname{LIN}(P<0.05)$ and the similarly low levels of LNA in CON and GS. The low level of polyphenols in the grape seed used in the present work, compared with those of other studies, could explain the lack of effect of this ingredient in increasing the concentration of LNA in milk of GS compared with CON, but does not explain the reduction in LNA in milk of MIX compared with that of LIN group. Therefore, considering that grape seed contains other compounds that could have affected the biohydrogenation of UFA, we hypothesize that the presence of grape seed might have increased, to some extent, the biohydrogenation of dietary PUFA, as suggested by the higher concentration of VA in MIX and by the higher concentration of VA in GS than in CON, even though these differences were not statistically significant $(P<$ $0.10)$. Our results are in accordance with the study of Moate et al. (2014), in which the milk concentration of LNA did not increase in lactating cows fed grape marc. The pattern of the concentration of PUFA n-3 mirrored that of LNA, with CON and GS having lower PUFA n-3 values than LIN, and MIX being intermediate $(P$ $<0.05)$.

The inclusion of grape seed and linseed in the diet of sheep, especially when offered in combination (MIX), increased the concentration of milk TFA compared with CON $(P<0.05)$. This result mirrored the increase in most of the individual TFA in those groups compared with CON, likely as a consequence of rumen biohydrogenation of PUFA, whose dietary concentration followed the increasing order CON $<$ GS $<$ LIN $<$ MIX (Table 1). This finding is in agreement with a previous study showing an increased concentration of TFA in milk when extruded linseed was included as a source of PUFA in the diet of dairy cows (Livingstone et al., 2015). These results were influenced the most by VA, which accounted for $34.21,40.42,43.59$, and $46.78 \%$ of the total TFA in milk from CON, GS, LIN, and MIX, respectively.

The total concentration of OBCFA decreased in the milk of the GS, LIN, and MIX groups compared with CON, being the lowest in MIX and intermediate in GS and LIN $(P<0.05)$. The OBCFA are mainly derived from the ruminal microflora (Fievez et al., 2012). The decrease in OBCFA in milk of LIN could be explained by the high amount of PUFA, particularly LNA, in linseed, considering that PUFA are reported to be toxic for the growth of ruminal microorganisms (Maia et al., $2007,2010)$. Similarly, the high concentration of LA in grape seed could explain the reduction in OBCFA in milk from GS compared with CON. Moreover, according to several studies showing the effect of polyphenols on the growth and activity of rumen microbial population (Vasta et al., 2010; Buccioni et al., 2015), the grape seed polyphenols could have contributed to this reduction. The high amount of PUFA, mainly LNA and LA, and the presence of polyphenols in the MIX diet could explain the lowest concentration of OBCFA found in the milk from sheep of this group, as confirmed by the previously reported results of the analysis on rumen liquid FA profile of the ewes of the dietary groups under comparison (Correddu et al., 2015). 
Table 2. Fatty acid profile of milk from sheep fed different experimental diets

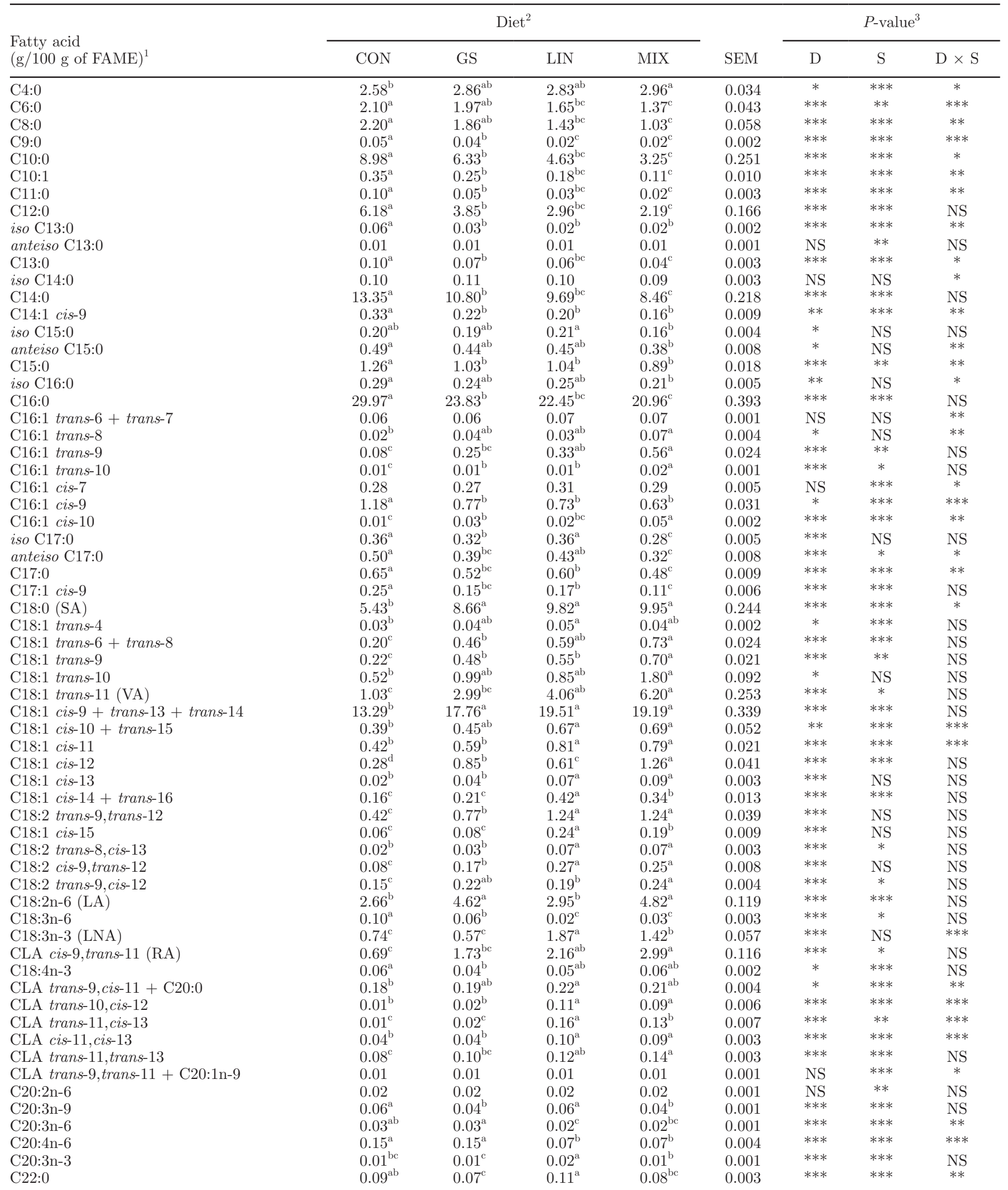


Table 2 (Continued). Fatty acid profile of milk from sheep fed different experimental diets

\begin{tabular}{|c|c|c|c|c|c|c|c|c|}
\hline $\begin{array}{l}\text { Fatty acid } \\
(\mathrm{g} / 100 \mathrm{~g} \text { of FAME })^{1}\end{array}$ & \multicolumn{4}{|c|}{$\operatorname{Diet}^{2}$} & SEM & \multicolumn{3}{|c|}{$P$-value ${ }^{3}$} \\
\hline $\mathrm{C} 20: 4 \mathrm{n}-3$ & $0.02^{\mathrm{ab}}$ & $0.01^{\mathrm{b}}$ & $0.02^{\mathrm{a}}$ & $0.02^{\mathrm{ab}}$ & 0.001 & $* *$ & $* * *$ & $* *$ \\
\hline C20:5n-3 (EPA) & $0.07^{\mathrm{a}}$ & $0.03^{\mathrm{c}}$ & $0.07^{\mathrm{a}}$ & $0.05^{\mathrm{b}}$ & 0.002 & $* * *$ & $* * *$ & $*$ \\
\hline $\mathrm{C} 22: 2 \mathrm{n}-6$ & $0.04^{\mathrm{a}}$ & $0.03^{\mathrm{b}}$ & $0.05^{\mathrm{a}}$ & $0.03^{\mathrm{b}}$ & 0.001 & $* * *$ & ** & ** \\
\hline $\mathrm{C} 22: 4 \mathrm{n}-6$ & $0.01^{\mathrm{ab}}$ & $0.01^{\mathrm{a}}$ & $0.00^{\mathrm{b}}$ & $0.00^{\mathrm{b}}$ & 0.001 & ** & $* * *$ & $* * *$ \\
\hline $\mathrm{C} 22: 6 \mathrm{n}-3$ (DHA) & 0.02 & 0.01 & 0.02 & 0.02 & 0.001 & NS & NS & NS \\
\hline \multicolumn{9}{|l|}{ Groups } \\
\hline SFA & $75.07^{\mathrm{a}}$ & $63.66^{\mathrm{b}}$ & $59.17^{\mathrm{b}}$ & $53.17^{\mathrm{c}}$ & 0.921 & $* * *$ & $* * *$ & NS \\
\hline UFA & $24.93^{\mathrm{c}}$ & $36.34^{\mathrm{b}}$ & $40.83^{\mathrm{b}}$ & $46.83^{\mathrm{a}}$ & 0.921 & $* * *$ & $* * *$ & NS \\
\hline MUFA & $19.20^{\mathrm{c}}$ & $27.36^{\mathrm{b}}$ & $30.85^{\mathrm{b}}$ & $34.71^{\mathrm{a}}$ & 0.652 & $* * *$ & $* * *$ & NS \\
\hline PUFA & $5.73^{\mathrm{c}}$ & $8.98^{\mathrm{b}}$ & $9.98^{\mathrm{ab}}$ & $12.12^{\mathrm{a}}$ & 0.283 & $* * *$ & $* * *$ & NS \\
\hline UFA:SFA & $0.33^{\mathrm{c}}$ & $0.58^{\mathrm{b}}$ & $0.70^{\mathrm{b}}$ & $0.90^{\mathrm{a}}$ & 0.025 & $* * *$ & $* * *$ & $*$ \\
\hline MCFA & $55.84^{\mathrm{a}}$ & $43.68^{\mathrm{b}}$ & $40.56^{\mathrm{b}}$ & $36.47^{\mathrm{c}}$ & 0.795 & $* * *$ & $* * *$ & NS \\
\hline LCFA & $27.90^{\mathrm{d}}$ & $43.01^{\mathrm{c}}$ & $48.71^{\mathrm{b}}$ & $54.80^{\mathrm{a}}$ & 1.110 & $* * *$ & $* * *$ & $*$ \\
\hline PUFA n-3 & $0.98^{\mathrm{c}}$ & $0.72^{\mathrm{c}}$ & $2.14^{\mathrm{a}}$ & $1.63^{\mathrm{b}}$ & 0.060 & $* * *$ & $*$ & $* * *$ \\
\hline PUFA n-6 & $3.00^{\mathrm{b}}$ & $4.92^{\mathrm{a}}$ & $3.13^{\mathrm{b}}$ & $4.99^{\mathrm{a}}$ & 0.118 & $* * *$ & $* * *$ & NS \\
\hline$n-6: n-3$ & $3.12^{\mathrm{b}}$ & $7.01^{\mathrm{a}}$ & $1.47^{\mathrm{c}}$ & $3.09^{\mathrm{b}}$ & 0.227 & $* * *$ & $* * *$ & $* * *$ \\
\hline Total CLA & $1.02^{\mathrm{c}}$ & $2.12^{\mathrm{bc}}$ & $2.88^{\mathrm{ab}}$ & $3.66^{\mathrm{a}}$ & 0.132 & $* * *$ & $* * *$ & NS \\
\hline Total C18:1 & $16.62^{\mathrm{c}}$ & $25.28^{\mathrm{b}}$ & $28.76^{\mathrm{b}}$ & $32.62^{\mathrm{a}}$ & 0.667 & $* * *$ & $* * *$ & NS \\
\hline Total C18:2 & $4.35^{\mathrm{c}}$ & $7.92^{\mathrm{b}}$ & $7.60^{\mathrm{b}}$ & $10.28^{\mathrm{a}}$ & 0.260 & $* * *$ & $* * *$ & NS \\
\hline \multicolumn{9}{|l|}{$\Delta^{9}$-desaturase indices } \\
\hline C10 index & 3.75 & 3.73 & 3.78 & 3.26 & 0.060 & NS & $* *$ & NS \\
\hline C14 index & 2.38 & 2.03 & 2.00 & 1.82 & 0.050 & NS & $*$ & $* *$ \\
\hline C16 index & 3.73 & 3.13 & 3.14 & 2.91 & 0.071 & NS & * & $* * *$ \\
\hline C18 index & $71.25^{\mathrm{a}}$ & $67.27^{\mathrm{ab}}$ & $66.65^{\mathrm{ab}}$ & $65.93^{\mathrm{b}}$ & 0.382 & $*$ & * & $*$ \\
\hline CLA cis-9,trans-11 index & $40.34^{\mathrm{a}}$ & $37.51^{\mathrm{ab}}$ & $34.79^{\mathrm{b}}$ & $33.20^{\mathrm{b}}$ & 0.444 & ** & NS & NS \\
\hline
\end{tabular}

\footnotetext{
${ }^{\mathrm{a}-\mathrm{d}}$ Means within a row with different superscripts are different $(P<0.05)$.
}

${ }^{1} \mathrm{SA}=$ stearic acid; VA = vaccenic acid; LA = linoleic acid; LNA = linolenic acid; RA = rumenic acid; EPA = eicosapentaenoic acid; DPA = docosapentaenoic acid; DHA = docosahexaenoic acid; SFA = sum of the individual saturated fatty acids reported in this table; UFA $=$ sum of the individual unsaturated fatty acids reported in this table; MUFA = sum of the individual monounsaturated fatty acids reported in this table; PUFA $=$ sum of the individual polyunsaturated fatty acids reported in this table; TFA $=$ trans fatty acids, sum of the individual trans fatty acids reported in this table, except CLA isomers; BCFA = branched-chain fatty acids, sum of iso- and anteiso-FA reported in this table; OBCFA = odd- and branched-chain fatty acids, sum of odd-, iso-, and anteiso-FA reported in this table; SCFA = short-chain fatty acids, sum of the individual fatty acids from C4:0 to C10:0 reported in this table; MCFA = medium-chain fatty acids, sum of the individual fatty acids from C11:0 to C17:0 reported in this table; LCFA = long-chain fatty acids, sum of the individual fatty acids from C18:0 to DHA reported in this table; PUFA n- 3 and PUFA n- $6=$ sum of individual n- 3 and n- 6 fatty acids, respectively, reported in this table; CLA = sum of individual conjugated linoleic acids reported in this table.

${ }^{2}$ Diets: $\mathrm{CON}=$ control diet; GS $=$ diet containing $300 \mathrm{~g} / \mathrm{d}$ per head of grape seed; LIN = diet containing $220 \mathrm{~g} / \mathrm{d}$ per head of linseed; MIX = diet containing $300 \mathrm{~g} / \mathrm{d}$ of grape seed and $220 \mathrm{~g} / \mathrm{d}$ of linseed per head.

${ }^{3} \mathrm{D}=$ effect of diet; $\mathrm{S}=$ effect of sampling date; $\mathrm{D} \times \mathrm{S}=$ effect of diet and sampling date interaction;

$\mathrm{NS}=P>0.05 ;{ }^{*} P<0.05 ; * * P<0.01 ; * * P<0.001$.

The inclusion of grape seed and linseed, alone and in combination, decreased $(P<0.05)$ the milk concentration of de novo synthesized FA C10:0, C12:0, and C14:0 compared with the CON group, probably due to the increase in the amount of PUFA in the diet of sheep, in accordance with previous studies in lactating sheep (Zhang et al., 2006), goats (Bernard et al., 2009), and cows (Chilliard et al., 2007). In addition, the concentrations of $\mathrm{C} 10: 1, \mathrm{C} 14: 1$ cis-9, C16:1 cis-9, and C17:1 cis-9 were also lower in the milk of GS, LIN, and
MIX compared with CON $(P<0.05)$. As suggested by Bernard et al. (2009), an increase in the amount of TFA and PUFA can reduce the activity of stearoyl CoA desaturase in the mammary gland and, consequently, the extent of $\Delta^{9}$-desaturation of C10:0, C14:0, C16:0, and $\mathrm{C} 17: 0$. The analysis of the desaturase indices partly confirmed these results. In particular, CON showed higher values of the C18 and CLA indices $(P<0.05)$ than MIX, with the other 2 groups being intermediate, whereas the C10, C14 and C16 indices were not signifi- 
1732

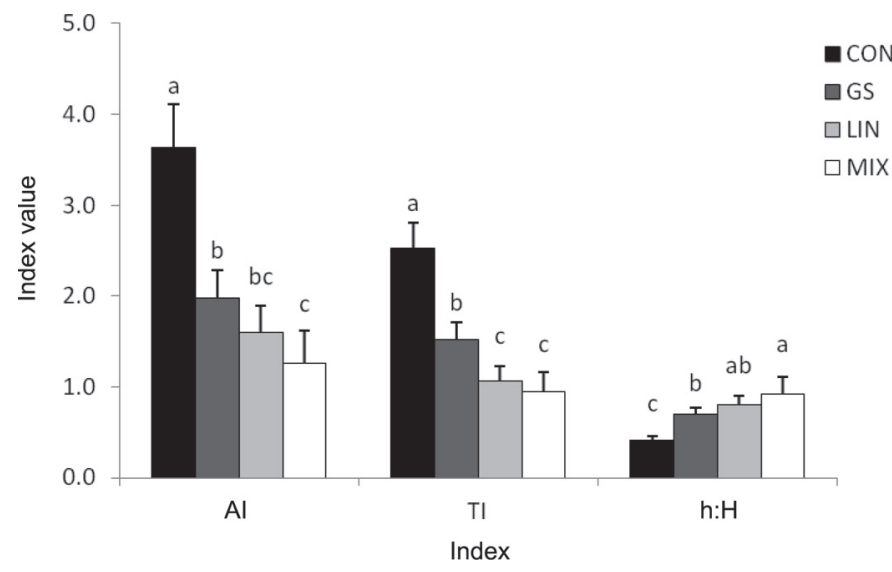

Figure 1. Effect of experimental diets on milk fat nutritional indices: atherogenic index (AI), thrombogenic index (TI), and hypocholesterolemic to hypercholesterolemic ratio $(\mathrm{h}: \mathrm{H}) \cdot \mathrm{CON}=$ control diet, GS = diet containing grape seed, LIN = diet containing linseed, MIX $=$ diet containing both grape seed and linseed. Values with different letters $(\mathrm{a}-\mathrm{c})$ within a variable $(\mathrm{AI}, \mathrm{TI}$, and $\mathrm{h}: \mathrm{H})$ indicate significant differences between experimental diets $(P<0.05)$. Error bars indicate standard deviation of the means of each group.

cantly influenced by the diets $(P>0.05)$. Although the concentrations of C18:1 cis-9 and CLA cis-9,trans-11 increased with the inclusion of grape seed and linseed, the DI related to these FA did not follow the same pattern, suggesting that the increase in these FA was related not to an increasing activity of $\Delta^{9}$-desaturase but, more likely, to the increase in the concentration of their substrates C18:0 and C18:1 trans-11. The total DI increased in all groups compared with $\mathrm{CON}(P<0.05)$, even if the individual DI followed an opposite trend. This is in contrast to the positive correlation between all DI (individual and total) observed by Schennink et al. (2008), and could be explained by differences be-

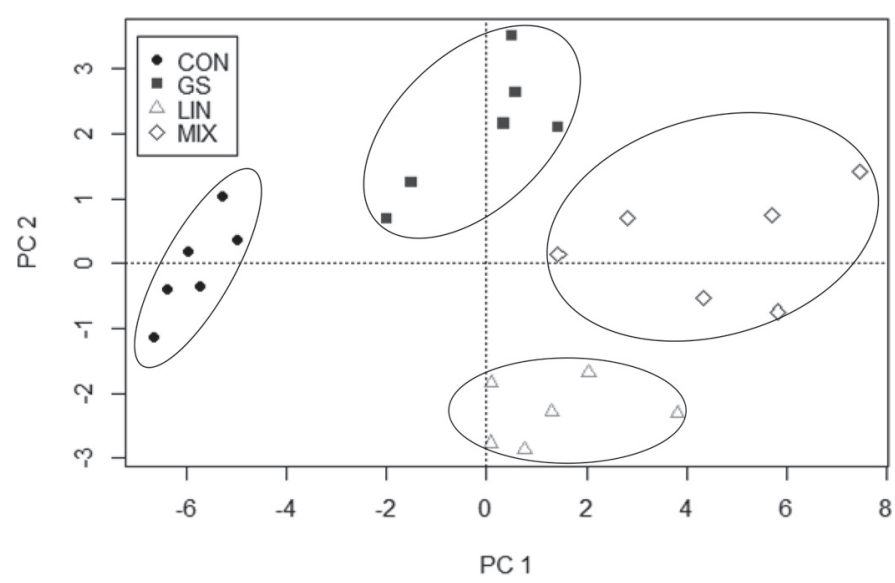

Figure 2. Plot of the scores of the first 2 principal components (PC) of individuals belonging to the different experimental diets. CON $=$ control diet, $\mathrm{GS}=$ diet containing grape seed, LIN = diet containing linseed, MIX = diet containing both grape seed and linseed. tween these studies in the ratio between C18:1 cis-9 and C16:0, which are the most abundant FA in milk. As noted by Schennink et al. (2008), the value of total DI mainly mirrors the ratio of $\mathrm{C} 18: 1$ cis-9 to $\mathrm{C} 16: 0$. The opposite trend between individual DI and total DI found in the present work suggests that total DI is not a reliable indicator of the desaturation activity of stearoyl Co-A desaturase.

As shown in Figure 1, the dietary inclusion of grape seed and linseed was effective in reducing the atherogenic and thrombogenic indices and increasing the $\mathrm{h}: \mathrm{H}$ ratio compared with $\mathrm{CON}(P<0.05)$. Our results are consistent with the fact that dietary sources of PUFA ameliorate cardiac risk factors (Duda et al., 2009; Katare and Saxena, 2013) and with a previous study in which dietary extruded linseed decreased the values

Table 3. Eigenvectors and eigenvalues of correlation matrix based on groups of milk fatty acids, sorted by decreasing values of the first principal component $(\mathrm{PC} 1)^{1}$

\begin{tabular}{lcc}
\hline Item $^{1}$ & PC1 & PC2 \\
\hline UFA & 0.246 & -0.027 \\
MUFA & 0.244 & -0.058 \\
Total C18:1 & 0.243 & -0.058 \\
LCFA & 0.243 & -0.055 \\
PUFA & 0.241 & 0.044 \\
Total C18:2 & 0.235 & 0.154 \\
TFA & 0.233 & 0.055 \\
Total CLA & 0.231 & -0.004 \\
h:H & 0.230 & -0.099 \\
Total C18:1-trans & 0.227 & 0.085 \\
Total C18:1-cis & 0.195 & -0.188 \\
PUFA n-6 & 0.158 & 0.455 \\
PUFA n-3 & 0.139 & -0.470 \\
n-6:n-3 & -0.021 & 0.559 \\
BCFA & -0.174 & -0.288 \\
OBCFA & -0.202 & -0.249 \\
SCFA & -0.231 & 0.108 \\
TI & -0.236 & 0.093 \\
MCFA & -0.238 & 0.030 \\
AI & -0.238 & 0.021 \\
SFA & -0.246 & 0.027 \\
Eigenvalues & 16.45 & 2.51 \\
Variance explained (\%) & 78.3 & 11.9
\end{tabular}

${ }^{1}$ UFA $=$ sum of the individual unsaturated fatty acids reported in Table 2; MUFA = sum of the individual monounsaturated fatty acids reported in Table 2; LCFA = long-chain fatty acids, sum of the individual fatty acids from C18:0 to docosahexaenoic acid reported in Table 2; PUFA $=$ sum of the individual polyunsaturated fatty acids reported in Table 2; TFA = trans fatty acids, sum of the individual trans fatty acids reported in Table 2 (except CLA isomers); total CLA = sum of individual conjugated linoleic acids reported in Table $2 ; \mathrm{h}: \mathrm{H}=$ hypocholesterolemic to hypercholesterolemic ratio; PUFA n- $6=$ sum of individual n- 6 fatty acids reported in Table 2; PUFA n- $3=$ sum of individual n-3 fatty acids reported in Table $2 ; \mathrm{BCFA}=$ branched-chain fatty acids reported in Table 2; OBCFA = odd- and branched-chain fatty acids reported in Table 2; SCFA = short-chain fatty acids, sum of the individual fatty acids from C4:0 to C10:0 reported in Table 2; $\mathrm{TI}=$ thrombogenic index; MCFA = medium-chain fatty acids, sum of the individual fatty acids from C11:0 to C17:0 reported in Table 2; $\mathrm{AI}=$ atherogenic index; $\mathrm{SFA}=$ sum of the individual saturated fatty acids reported in Table 2. 
of $\mathrm{AI}$ and $\mathrm{TI}$ and increased the h:H ratio in dairy goats (Nudda et al., 2013a). Similar results were found in Lacaune ewes fed extruded linseed (Casamassima et al., 2014). The effect of the dietary inclusion of grape seed on these indices was likely related to the large decrease in C12:0, C14:0, and C16:0 and increase in MUFA. The values of TI were lower in LIN than in GS $(P<0.05)$, suggesting that the inclusion of linseed is more effective in increasing the concentration of beneficial FA compared with grape seed. Grape seed and linseed in combination (MIX) led to lower values of AI and TI, and a higher value of $\mathrm{h}: \mathrm{H}$ than grape seed alone $(P<$ 0.05). Moreover, the reduction in AI and TI and the increase in $\mathrm{h}: \mathrm{H}$ were numerically higher, although not statistically different, in MIX than in LIN, suggesting a summative effect of linseed and grape seed. The substantial improvement in milk FA due to the combined effect of grape seed and linseed was evidenced by the 65.33 and $62.61 \%$ decreases in AI and TI, respectively, and by the $125 \%$ increase in h:H in MIX compared with CON.

Most of the FA measured during the trial were influenced by sampling date, with FA of the same class generally showing a similar pattern (data not shown). In particular, most of the SFA, SCFA, and MCFA showed a significant decrease $(P<0.05)$ in the second and third samplings compared with the first and last samplings, whereas most of the UFA, MUFA, PUFA, and LCFA showed an opposite trend, with the second and third samplings showing greater values than the first and last samplings $(P<0.05)$. Although many of the FA were significantly influenced by the $\mathrm{D} \times \mathrm{S}$ interaction $(P<0.05)$, the few differences observed in the temporal pattern among dietary treatments (data not shown) was not relevant compared with the main effect of the diet on FA concentration.

\section{Multivariate Analysis}

The results of the PCA are shown in Table 3 and Figure 2. Two principal components (PC) were retained for subsequent analysis based on the proportion of variance explained by each PC. The first and second

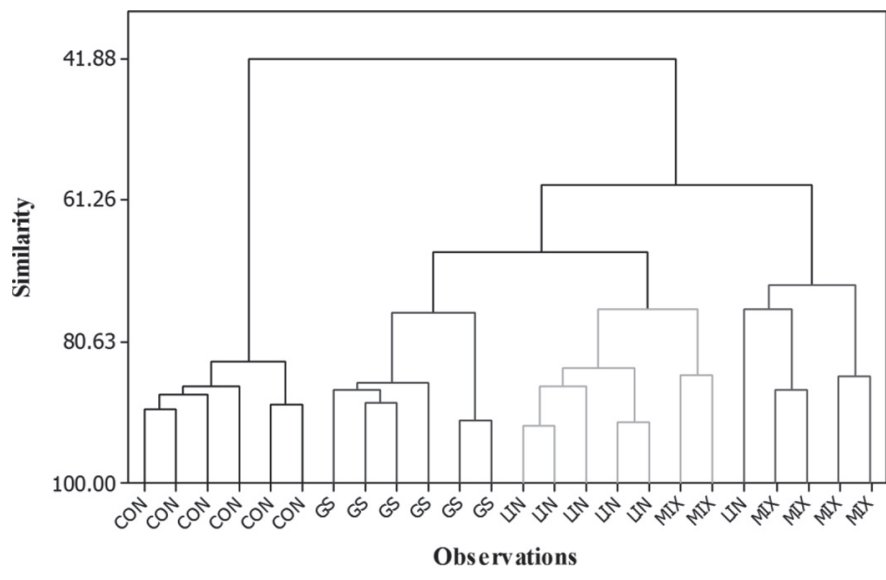

Figure 3. Hierarchical cluster analysis results for milk of the 4 dietary treatments. $\mathrm{CON}=$ control diet, $\mathrm{GS}=$ diet containing grape seed, LIN = diet containing linseed, MIX = diet containing both grape seed and linseed. Data are from groups of fatty acids + nutritional indices.

PC accounted for about $90 \%$ of the total variability ( 78 and $12 \%$, respectively). Table 3 shows the eigenvalues and eigenvectors of the correlation matrix derived from groups of FA in milk. The PC1 was positively associated with the groups of FA characterized by long and unsaturated chains, whereas it was negatively associated with groups characterized by short- and medium-chain FA and SFA. The PC1 was also positively correlated with the sum of $\mathrm{C} 18: 1$ and C18:2 isomers and, among $\mathrm{C} 18: 1$, the trans isomers showed a greater correlation than the cis isomers. According to previous studies on dairy cows, dietary supplementation with vegetable oils as a source of PUFA increases the concentration of long-chain PUFA n-3 (Ferlay et al., 2013) or PUFA n-6 (Almeida et al., 2013) and decreases the concentration of short- and medium-chain FA in milk. Among PUFA, PC2 loadings were positively correlated with n-6 and with n-6:n-3 ratio, and negatively with n-3. Moreover, $\mathrm{PC} 2$ negatively discriminated the OBCFA and BCFA. $\mathrm{PC} 1$ showed high positive loadings for the h:H ratio and high negative loadings for $\mathrm{AI}$ and TI. The PC2, to a lesser extent, was positively correlated with $\mathrm{AI}$ and $\mathrm{TI}$ and negatively with the h:H ratio.

Table 4. Dietary effects on principal component (PC) scores of individuals belonging to the different dietary treatments for PC1 (PUFA intake) and PC2 (n-6:n-3)

\begin{tabular}{llcccccc}
\hline & \multicolumn{9}{c}{ Diet $^{1}$} & & \multicolumn{2}{c}{$P$-value } \\
\cline { 2 - 5 } Item & CON & GS & LIN & MIX & & SEM & Diet \\
\hline PC1 & $-5.7720^{\mathrm{d}}$ & $-0.2671^{\mathrm{c}}$ & $1.5283^{\mathrm{b}}$ & $4.5108^{\mathrm{a}}$ & 0.5905 & $<0.0001$ \\
PC2 & $-0.1499^{\mathrm{b}}$ & $1.8599^{\mathrm{a}}$ & $-2.0293^{\mathrm{c}}$ & $0.3193^{\mathrm{b}}$ & & 0.3105 & $<0.0001$ \\
\hline
\end{tabular}

a-d Means within a row with different superscripts are different $(P<0.05)$.

${ }^{1}$ Diets: CON $=$ control diet; GS $=$ diet containing $300 \mathrm{~g} / \mathrm{d}$ per animal of grape seed; LIN = diet containing $220 \mathrm{~g} / \mathrm{d}$ per animal of linseed; MIX = diet containing $300 \mathrm{~g} / \mathrm{d}$ of grape seed and $220 \mathrm{~g} / \mathrm{d}$ of linseed per animal. 
The plot of the first $2 \mathrm{PC}$ scores allows us to describe the relationship among animals based exclusively on the milk FA profile (Figure 2). Four clusters were identified according to the 4 dietary treatments, with $\mathrm{CON}$ being the most isolated group and being mainly discriminated by PC1 (negative scores). The PC2 scores discriminated GS (positive scores) from LIN (negative scores). We propose that PC1 was positively associated with dietary inclusion of PUFA, especially with PUFA intake $(\mathrm{CON}<\mathrm{GS}<\mathrm{LIN}<\mathrm{MIX}$, as previously reported in Correddu et al., 2015); therefore, PC1 was named "PUFA intake." The $\mathrm{PC} 2$ could be related to the different sources of PUFA (grape seed or linseed) and consequently, to the PUFA n-6:n-3 ratio in the diets; thus, $\mathrm{PC} 2$ was identified as the "n- 6 to n- 3 ratio." Similar results were reported in the work of Bernard et al. (2009), who investigated the effects of sunflower and linseed oils, characterized by high LA and LNA content, respectively, on goat milk FA composition. In that study, the analysis of principal components, used to clarify the relationship between the oil treatments, forages, and milk production and composition, showed that PC1 was related to lipid supplementation, and $\mathrm{PC} 2$ was related to the content of LA and LNA in the diets.

The results of the HCA performed in the present study are shown in Figure 3. The dendrogram allowed us to group the animals in 4 clusters, with a $72.80 \%$ similarity level. The animals of CON formed a unique cluster, indicating that the chemical composition of milk from this group was different from that of the other groups. Another unique cluster grouped the animals of GS, indicating that the chemical composition of milk from sheep fed grape seed was different from that of CON and of sheep fed linseed (LIN and MIX). The animals of the LIN and MIX groups formed 2 clusters, except for a few cases of incorrect assignation: 2 animals of the MIX treatment were assigned to the LIN group, and 1 animal of the LIN treatment was assigned to the MIX group. This suggests that the chemical composition of the milk from sheep fed linseed (LIN and MIX) was different from that of the CON and GS groups. The clustering of animals in the 4 dietary treatments evidenced by the plot of PC (Figure 2) and by the dendrogram (Figure 3) was confirmed by the results of the statistical analysis of the relationship between dietary groups and PC1 and PC2 reported in Table 4.

\section{CONCLUSIONS}

Dietary inclusion of grape seed or linseed, or both, improved milk FA composition in Sarda dairy ewes, and the multivariate approach allowed us to detect differences between dietary treatments based on the milk fatty acid profile. When grape seed was supplied alone, at $300 \mathrm{~g} / \mathrm{d}$ per animal, the milk content of SFA decreased and that of UFA and PUFA increased, mainly due to a large increase of LA, whereas the concentrations of RA and VA tended to increase compared with the control group. The inclusion of $200 \mathrm{~g} / \mathrm{d}$ per animal of linseed alone increased the concentration of potentially beneficial FA, such as oleic acid, linolenic acid, and CLA cis-9,trans-11. The inclusion of grape seed and linseed in combination resulted in a major increase of ratios UFA:SFA and PUFA:SFA and in the concentration of CLA cis-9,trans-11. The use of grape seed in sheep diets could avoid disposal of this by-product, and its combination with linseed could be a successful strategy to enhance PUFA in lactating Sarda ewes.

\section{ACKNOWLEDGMENTS}

The authors thank Ana Helena Dias Francesconi, from the University of Sassari, for revising the manuscript; Antonio Fenu, Antonio Mazza, Roberto Rubattu, and Gesumino Spanu, from the University of Sassari, for technical assistance; the Azienda Ledda (Sassari, Italy) for making the farm and animals available, and Giovanni Pinna from Cargill s.r.l. (Animal Nutrition Division, Milan, Italy) for providing the feed ingredients.

\section{REFERENCES}

Almeida, O. C., A. V. Pires, I. Susin, R. S. Gentil, C. Q. Mendes, M. A. A. Queiroz, E. M. Ferreira, and M. L. Eastridge. 2013. Milk fatty acids profile and arterial blood milk fat precursors concentration of dairy goats fed increasing doses of soybean oil. Small Rumin. Res. 114:152-160.

Bernard, L., K. J. Shingfield, J. Rouel, A. Ferlay, and Y. Chilliard. 2009. Effect of plant oils in the diet on performance and milk fatty acid composition in goats fed diets based on grass hay or maize silage. Br. J. Nutr. 101:213-224.

Bhattacharya, A., J. Banu, M. Rahman, J. Causey, and G. Fernandes. 2006. Biological effects of conjugated linoleic acids in health and disease. J. Nutr. Biochem. 17:789-810.

Buccioni, A., M. Pauselli, C. Viti, S. Minieri, G. Pallara, V. Roscini, S. Rapaccini, M. Trabalza Marinucci, P. Lupi, G. Conte, and M. Mele. 2015. Milk fatty acid composition, rumen microbial population, and animal performances in response to diets rich in linoleic acid supplemented with chestnut or quebracho tannins in dairy ewes. J. Dairy Sci. 98:1145-1156.

Cabiddu, A., G. Molle, M. Decandia, S. Spada, M. Fiori, G. Piredda, and M. Addis. 2009. Responses to condensed tannins of flowering sulla (Hedysarum coronarium L.) grazed by dairy sheep: Part 2: Effects on milk fatty acid profile. Livest. Sci. 123:230-240.

Caroprese, M., A. Marzano, R. Marino, G. Gliatta, A. Muscio, and A. Sevi. 2010. Flaxseed supplementation improves fatty acid profile of cow milk. J. Dairy Sci. 93:2580-2588.

Casamassima, D., M. Nardoia, M. Palazzo, F. Vizzarri, A. G. D'Alessandro, and C. Corino. 2014. Effect of dietary extruded linseed, verbascoside and vitamin E supplements on yield and quality of milk in Lacaune ewes. J. Dairy Res. 81:485-493.

Chilliard, Y., F. Glasser, A. Ferlay, L. Bernard, J. Rouel, and M. Doreau. 2007. Diet, rumen biohydrogenation and nutritional quality of cow and goat milk fat. Eur. J. Lipid Sci. Technol. 109:828855 . 
Coltro, W. K., M. M. Ferreira, F. A. Macedo, C. C. Oliveira, J. V. Visentainer, N. E. Souza, and M. Matsushita. 2005. Correlation of animal diet and fatty acid content in young goat meat by gas chromatography and chemometrics. Meat Sci. 71:358-363.

Correddu, F., A. Nudda, G. Battacone, R. Boe, A. H. D. Francesconi, and G. Pulina. 2015. Effects of grape seed supplementation, alone or associated with linseed, on ruminal metabolism in Sarda dairy sheep. Anim. Feed Sci. Technol. 199:61-72.

Dschaak, C. M., C. M. Williams, M. S. Holt, J.-S. Eun, A. J. Young, and B. R. Min. 2011. Effects of supplementing condensed tannin extract on intake, digestion, ruminal fermentation, and milk production of lactating dairy cows. J. Dairy Sci. 94:2508-2519.

Duda, M. K., K. M. O'Shea, and W. C. Stanley. 2009. w-3 polyunsaturated fatty acid supplementation for the treatment of heart failure: Mechanisms and clinical potential. Cardiovasc. Res. 84:33-41.

Ferlay, A., M. Doreau, C. Martin, and Y. Chilliard. 2013. Effects of incremental amounts of extruded linseed on the milk fatty acid composition of dairy cows receiving hay or corn silage. J. Dairy Sci. 96:6577-6595.

Fernández, M., J. A. Ordóñez, I. Cambero, C. Santos, C. Pin, and L. de la Hoz. 2007. Fatty acid compositions of selected varieties of Spanish dry ham related to their nutritional implications. Food Chem. 101:107-112.

Fievez, V., E. Colman, J. M. Castro-Montoya, I. Stefanov, and B. Vlaeminck. 2012. Milk odd- and branched-chain fatty acids as biomarkers of rumen function-An update. Anim. Feed Sci. Technol. 172:51-65.

Gómez-Cortés, P., A. Bach, P. Luna, M. Juárez, and M. A. de la Fuente. 2009. Effects of extruded linseed supplementation on n-3 fatty acids and conjugated linoleic acid in milk and cheese from ewes. J. Dairy Sci. 92:4122-4134.

Griinari, J. M., and D. E. Bauman. 1999. Biosynthesis of conjugated linoleic acid and its incorporation into meat and milk in ruminants. Pages 180-200 in Advances in Conjugated Linoleic Acid Research, Vol. 1. M. P. Yurawecz, M. M. Mossoba, J. K. G Kramer, M. W. Pariza, and G. J. Nelson, ed. AOCS Press, Champaign, IL.

Kadegowda, A. K., L. S. Piperova, and R. A. Erdman. 2008. Principal component and multivariate analysis of milk long-chain fatty acid composition during diet-induced milk fat depression. J. Dairy Sci. 91:749-759.

Katare, C., and S. Saxena. 2013. Amelioration of selected cardiac risk factors through supplementation of diet with flaxseed and soya bean. Int. J. Nut. Pharmacol. Neurol. Dis. 3:352-357.

Kennelly, J. J. 1996. The fatty acid composition of milk fat as influenced by feeding oilseeds. Anim. Feed Sci. Technol. 60:137-152.

Khiaosa-Ard, R., S. F. Bryner, M. R. L. Scheeder, H. R. Wettstein, F. Leiber, M. Kreuzer, and C. R. Soliva. 2009. Evidence for the inhibition of the terminal step of ruminal $\alpha$-linolenic acid biohydrogenation by condensed tannins. J. Dairy Sci. 92:177-188.

Livingstone, K. M., D. J. Humphries, P. Kirton, K. E. Kliem, D. I. Givens, and C. K. Reynolds. 2015. Effects of forage type and extruded linseed supplementation on methane production and milk fatty acid composition of lactating dairy cows. J. Dairy Sci. 98:4000-4011.

Maia, M. R. G., L. C. Chaudhary, C. S. Bestwick, A. J. Richardson, N. McKain, T. R. Larson, I. A. Graham, and R. J. Wallace. 2010. Toxicity of unsaturated fatty acids to the biohydrogenating ruminal bacterium, Butyrivibrio fibrisolvens. BMC Microbiol. 10:52.

Maia, M. R. G., L. C. Chaudhary, L. Figueres, and R. J. Wallace. 2007. Metabolism of polyunsaturated fatty acids and their toxicity to the microflora of the rumen. Antonie van Leeuwenhoek 91:303-314

Mele, M., A. Serra, G. Conte, A. Pollicardo, M. del Viva, and P. Secchiari. 2007. Whole extruded linseed in the diet of dairy ewes during early lactation: Effect on the fatty acid composition of milk and cheese. Ital. J. Anim. Sci. 6:560-562.

Minieri, S., A. Buccioni, S. Rapaccini, A. Pezzati, D. Benvenuti, A. Serra, and M. Mele. 2014. Effect of Quebracho tannin extract on soybean and linseed oil biohydrogenation by solid associated bacteria: an in vitro study. Ital. J. Anim. Sci. 13:604-608.
Moate, P. J., S. R. O. Williams, V. A. Torok, M. C. Hannah, B. E. Ribaux, M. H. Tavendale, R. J. Eckard, J. L. Jacobs, M. J. Auldist, and W. J. Wales. 2014. Grape marc reduces methane emissions when fed to dairy cows. J. Dairy Sci. 97:5073-5087.

Mozaffarian, D., R. Micha, and S. Wallace. 2010. Effects on coronary heart disease of increasing polyunsaturated fat in place of saturated fat: a systematic review and meta-analysis of randomized controlled trials. PLoS Med. 7:e1000252.

Mozzon, M., N. G. Frega, B. Fronte, and M. Tocchini. 2002. Effect of dietary fish oil supplements on levels of n-3 polyunsaturated fatty acids, trans acids and conjugated linoleic acid in ewe milk. Food Technol. Biotechnol. 40:213-219.

Mughetti, L., F. Sinesio, G. Acuti, C. Antonini, E. Moneta, M. Peparaio, and M. Trabalza-Marinucci. 2012. Integration of extruded linseed into dairy sheep diets: Effects on milk composition and quality and sensorial properties of Pecorino cheese. Anim. Feed Sci. Technol. 178:27-39.

Nudda, A., G. Battacone, A. S. Atzori, C. Dimauro, S. P. G. Rassu, P. Nicolussi, P. Bonelli, and G. Pulina. 2013a. Effect of extruded linseed supplementation on blood metabolic profile and milk performance of Saanen goats. Animal 7:1464-1471.

Nudda, A., G. Battacone, O. Boaventura Neto, A. Cannas, A. H. D. Francesconi, A. S. Atzori, and G. Pulina. 2014. Feeding strategies to design the fatty acid profile of sheep milk and cheese. Rev. Bras. Zootec. 43:445-456.

Nudda, A., G. Battacone, R. Boe, M. G. Manca, S. P. G. Rassu, and G. Pulina. 2013b. Influence of outdoor and indoor rearing system of suckling lambs on fatty acid profile and lipid oxidation of raw and cooked meat. Ital. J. Anim. Sci. 12:459-467.

Nudda, A., G. Battacone, M. G. Usai, S. Fancellu, and G. Pulina. 2006. Supplementation with extruded linseed cake affects concentrations of conjugated linolenic acid and vaccenic acid in goat milk. J. Dairy Sci. 89:277-282.

Nudda, A., M. A. McGuire, G. Battacone, and G. Pulina. 2005. Seasonal variation in conjugated linoleic acid and vaccenic acid in milk fat of sheep and its transfer to cheese and ricotta. J. Dairy Sci. 88:1311-1319.

Santos, N. W., G. T. D. Santos, D. C. Silva-Kazama, P. A. Grande, P. M. Pintro, F. E. de Marchi, C. C. Jobim, and H. V. Petit. 2014 Production, composition and antioxidants in milk of dairy cows fed diets containing soybean oil and grape residue silage. Livest. Sci. 159:37-45.

Schennink, A., J. M. L. Heck, H. Bovenhuis, M. H. P. W. Visker, H. J. F. van Valenberg, and J. A. M. van Arendonk. 2008. Milk fatty acid unsaturation: Genetic parameters and effects of stearoyl-CoA desaturase $(S C D 1)$ and acyl CoA:diacylglycerol acyltransferase 1 (DGAT1). J. Dairy Sci. 91:2135-2143.

Schieber, A., F. C. Stintzing, and R. Carle. 2001. By-products of plant food processing as a source of functional compounds-Recent developments. Trends Food Sci. Technol. 12:401-413.

Simopoulos, A. P. 1991. Omega-3 fatty acids in health and disease and in growth and development. Am. J. Clin. Nutr. 54:438-463.

Ulbricht, T. L. V., and D. A. T. Southgate. 1991. Coronary heart disease: Seven dietary factors. Lancet 338:985-992.

Vasta, V., H. P. S. Makkar, M. Mele, and A. Priolo. 2009a. Ruminal biohydrogenation as affected by tannins in vitro. Br. J. Nutr. 102:82-92.

Vasta, V., M. Mele, A. Serra, M. Scerra, G. Luciano, M. Lanza, and A. Priolo. 2009b. Metabolic fate of fatty acids involved in ruminal biohydrogenation in sheep fed concentrate or herbage with or without tannins. J. Anim. Sci. 87:2674-2684.

Vasta, V., D. R. Yáñez-Ruiz, M. Mele, A. Serra, G. Luciano, M. Lanza, L. Biondi, and A. Priolo. 2010. Bacterial and protozoal communities and fatty acid profile in the rumen of sheep fed a diet containing added tannins. Appl. Environ. Microbiol. 76:2549-2555.

Zhang, R. H., A. F. Mustafa, and X. Zhao. 2006. Effects of feeding oilseeds rich in linoleic and linolenic fatty acids to lactating ewes on cheese yield and on fatty acid composition of milk and cheese. Anim. Feed Sci. Technol. 127:220-233. 